\title{
Decrease in Central Venous Catheter Placement and Complications Due to Utilization of Ultrasound-Guided Peripheral Intravenous Catheters
}

\author{
Arthur K Au \\ Thomas Jefferson University \\ Masashi Rotte \\ Thomas Jefferson University \\ Robert Grzybowski \\ Thomas Jefferson University \\ Bon $\mathrm{Ku}$

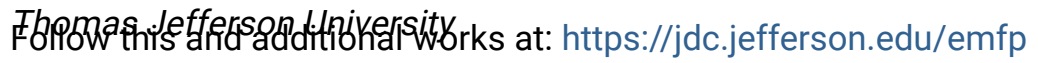 \\ SPemtMf trieldshergency Medicine Commons \\ Themas isfeferso universitw access to this document benefits you
}

\section{Recommended Citation}

Au, Arthur K; Rotte, Masashi; Grzybowski, Robert; Ku, Bon; and Fields, Jason M., "Decrease in Central Venous Catheter Placement and Complications Due to Utilization of Ultrasound-Guided Peripheral Intravenous Catheters" (2012). Department of Emergency Medicine Faculty Papers. Paper 14.

https://jdc.jefferson.edu/emfp/14

This Article is brought to you for free and open access by the Jefferson Digital Commons. The Jefferson Digital Commons is a service of Thomas Jefferson University's Center for Teaching and Learning (CTL). The Commons is a showcase for Jefferson books and journals, peer-reviewed scholarly publications, unique historical collections from the University archives, and teaching tools. The Jefferson Digital Commons allows researchers and interested readers anywhere in the world to learn about and keep up to date with Jefferson scholarship. This article has been accepted for inclusion in Department of Emergency Medicine Faculty Papers by an authorized administrator of the Jefferson Digital Commons. For more information, please contact: JeffersonDigitalCommons@jefferson.edu. 


\section{Jefferson. \\ Decrease in Central Venous Catheter Placement and Complications Due to Utilization of Ultrasound-Guided Peripheral Intravenous Catheters \\ Arthur Au MD, Masashi Rotte MD, Robert Grzybowski, Bon Ku MD MPP, J. Matthew Fields MD}

Thomas Jefferson University Hospital, Department of Emergency Medicine, Philadelphia, PA

\section{INTRODUCTION}

- Up to $40 \%$ of ED visits include diagnostic blood tests and $26 \%$ result in administration of IV fluids necessitating successful peripheral intravenous (IV) catheter placement.'

- There is a subset of patients with difficult IV access (DIVA) in which traditional cannulation methods are unsuccessful resulting in central venous cannulation (CVC).

- CVCs have a 5-15 percent complication rate ${ }^{2}$ and attributable costs per $\mathrm{CVC}$ related infection have been estimated at $\$ 34,508-\$ 56,0000^{3}$

- Ultrasound-guided peripheral IV catheters (USGPIVs) provide a method of potentially decreasing the need for $\mathrm{CVC}$ placement, however due to poor durability of USGPIVs the actual reduction in CVCs is unclear.

- This study set out to quantify the reduction in CVCs in patients with DIVA by utilization of USGPIVs.

\section{METHODS}

- Study Design: Prospective observational study of patients with difficult IV access.

- Setting: Two urban Emergency Departments with annual censuses of 65,000 and 40,000. Enrollment occurred from November 2010 - June 2011.

- Population: Convenience sample of patients with at least two failed peripheral IV attempts plus a failure to establish extrajugular access (failure, patient refusal, or inability to lay supine) determined to require $\mathrm{CVC}$ for IV access if ultrasound was not available were included. Patients were excluded if unable to give verbal consent, if $\mathrm{CVC}$ was determined to be required for patient stabilization or if the caring physician indicated tha a CVC would not be necessary despite the failure to establish peripheral IV access.

- Protocol: USGPIVs were placed by ED physicians at all levels of training. All USGPIVs were 20GA $48 \mathrm{~mm}$ long catheters placed using a Sonosite Micromaxx or M-Turbo (Sonosite Inc., Bothell, WA) high-frequency linear array transducer. Patients were followed for 7 days or until hospital discharge to assess for subsequent central venous access and related complications.

\section{Figure 1: USGPIV placement and outcomes}

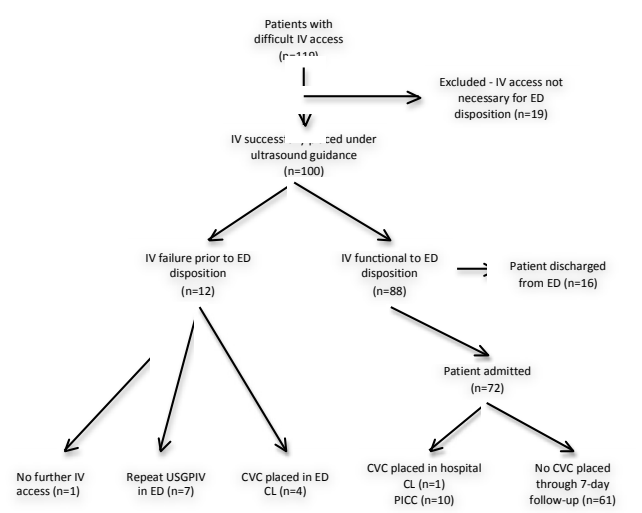

(USGPIV - ultrasound guided peripheral IV catheter, CVC- central venous catheter, $\mathrm{CL}$ - central line,
PICC - peripherally inserted central catheter)

\section{RESULTS}

- 119 patients underwent USGPIV by 22 different physicians. - 19 patients excluded from data analysis because the ED provider felt they would not have
required CVC placement even if USGPIV placement had failed, yielding 100 patients for analysis.

- USGPIVs failed in 12 (12.0\%, 95 CI: 7.0-19.8\%) patients prior to ED disposition, resulting in 4 central venous catheters, 7 repeated USGPIVs and one patient requiring no

- Overall a total of 15 (15.0\%, 95 CI: 9.3-23.3\%) patients underwent central venous access (5 central lines and 10 PICCs)

- Four (4.0\%, 95 CI: 1.6-9.8\%) patients had documented complications due to USGPIV (3 extravasation of fluids, 1 extravasation of IV contrast

- One patient in the $\mathrm{CVC}$ group developed a catheter related infection resulting in a $6.7 \%$ (95 CI: 1.2-29.8\%) complication rate.

\section{Table 1: Characteristics of patients requiring USGPIV}

\begin{tabular}{|ll|}
\hline \multicolumn{2}{|l|}{$\mathrm{N}=100$} \\
\hline Sex & 44 \\
\hline Male & 56 \\
\hline Female & \\
\hline Race & 62 \\
\hline African American & 32 \\
\hline Caucasian & \\
\hline History & 9 \\
\hline IV Drug Abuse & 46 \\
\hline Hypertension & 35 \\
\hline Diabetes & 11 \\
\hline Dialysis & 83 \\
\hline Prior Difficult IV Access & 39 \\
\hline Obese & 7 \\
\hline Chemotherapy & \\
\hline
\end{tabular}

LIMITATIONS

- No randomization or blinding.

- Underpowered to assess the true complication rates of CVCs.

- Potential bias in determining necessity of central venous access.

\section{CONCLUSIONS}

Ultrasound prevents the need for central venous access in approximately $85 \%$ of patients Ultrasound prevents the
with difficult IV access.

- Assuming a standard CVC complication rate of 5-15\% in the DIVA cohort, by avoiding VVC placement in $85 \%$ of this cohort, USGPIVs potentially reduce significant

- For every eight patients with DIVA that get an USGPIV instead of a CVC, at least one CVC complication is avoided 